\title{
Følges retningslinjene for behandling av hjerteinfarkt?
}

\begin{abstract}
BAKGRUNN Nye retningslinjer anbefaler tidlig invasiv utredning og behandling av de fleste pasienter med akutt hjerteinfarkt - også pasienter med hjerteinfarkt uten ST-elevasjon på EKG. I denne studien har vi undersøkt etterlevelsen av disse behandlingsretningslinjene ved Sørlandet sykehus Arendal.
\end{abstract}

MATERIALE OG METODE Alle pasienter innlagt ved Sørlandet sykehus Arendal i 2012 med akutt hjerteinfarkt ble registrert i Norsk hjerteinfarktregister. Data fra registeret er benyttet til å analysere tidsforløpet fra symptomdebut til koronar angiografi og revaskularisering.

RESULTATER I 2012 ble 788 pasienter innlagt med akutt hjerteinfarkt ved Sørlandet sykehus Arendal. Av disse hadde 269 (34,1\%) ST-elevasjonsinfarkt (STEMI) og 519 (65,9\%) ikke-STelevasjonsinfarkt (nSTEMI). De fleste pasienter med ST-elevasjonsinfarkt $(220(81,8 \%))$ ble direkte innlagt på Sørlandet sykehus Arendal, og blant disse var median tid fra innleggelse til revaskularisering 31 minutter. 347 (66,9\%) av pasientene med ikke-ST-elevasjonsinfarkt ble først innlagt på lokalsykehus før de ble overflyttet til Sørlandet sykehus Arendal. Kun fire $(1,2 \%)$ av disse fikk angiografi innen to timer fra innleggelse ved første sykehus. 13 (9,0\%) av pasientene med ikke-ST-elevasjonsinfarkt som ble direkte innlagt og angiografert ( $n=144$ ), ble angiografert innen to timer etter innleggelse. Angiografi ble utført innen 24 timer hos $119(34,3 \%)$ av overflyttede $(n=347)$ og hos $82(56,9 \%)$ av direkte innlagte pasienter som ble angiografert $(n=144)$.

FORTOLKNING Mange pasienter med ikke-ST-elevasjonsinfarkt kommer ikke til revaskulariserende behandling med perkutan koronar intervensjon (PCI) innenfor anbefalte tidsrammer. Flere pasienter med sterk klinisk mistanke om akutt hjerteinfarkt bør innlegges direkte på sykehus med PCl-beredskap.

Hvert år får 12-15 000 nordmenn hjerteinfarkt (1). Behandlingsstrategien ved mistanke om akutt hjerteinfarkt har tidligere hovedsakelig vært avhengig av om EKG viser ST-elevasjon eller ikke. Nytten av tidlig revaskularisering med perkutan koronar intervensjon (PCI) eller trombolytisk behandling er veldokumentert ved ST-elevasjonsinfarkt i EKG (STEMI), der de fleste pasientene har akutt koronar okklusjon $(2,3)$. De siste årene er det vist at EKG alene ikke identifiserer akutt koronar okklusjon hos alle pasienter $(4,5)$. Også ved mange hjerteinfarkt uten ST-elevasjon i EKG (nSTEMI) påvises koronar okklusjon ved koronar angiografi (6, 7). Denne typen er hyppigere (8) og har dårligere langtidsprognose (9) enn ST-elevasjonsinfarkt. Revaskularisering ved perkutan koronar intervensjon (PCI) fjerner symptomer, forkorter sykehusopphold og bedrer prognosen også ved ikke-ST-elevasjonsinfarkt $(10,11)$.

European Society of Cardiology (ESC) publiserte nye retningslinjer for behandling av pasienter med akutt koronar syndrom uten ST-elevasjon i EKG i 2011 (12) og nye retningslinjer for behandling av hjerteinfarkt med ST-elevasjon i 2012 (13). Retningslinjene ble umiddelbart implementert i lokale prosedyrer i vårt sykehusområde. De er også anbefalt tatt i bruk av Norsk Cardiologisk
Selskap (14) og senere av det regionale kardiologiutvalget i Helse Sør-Øst (15). Tidligere invasiv utredning og behandling av pasienter med ikke-ST-elevasjonsinfarkt i EKG er en viktig endring i de nye retningslinjene (ramme 1). Hastegraden for koronar angiografi ved denne typen anbefales satt på bakgrunn av en systematisk risikovurdering (12). Pasienter med behandlingsrefraktære brystsmerter, residiverende brystsmerter med ST-depresjon eller dyp negativ T-bølge på EKG til tross for antianginøs behandling, kliniske symptomer på hjertesvikt eller hemodynamisk instabilitet (sjokk) eller med livstruende arytmier defineres som svært høy risiko og bør til umiddelbar koronar angiografi, dvs. innen to timer fra første medisinske vurdering (prehospital eller ved ankomst sykehus) (12).

De øvrige pasientene med ikke-ST-elevasjonsinfarkt anbefales tidlig koronar angiografi, dvs. innen 24 timer fra første medisinske vurdering (ramme 1) (12). Retningslinjene omhandler også pasienter med akutt koronarsyndrom uten hjerteinfarkt, og disse anbefales eventuell invasiv utredning avhengig av risikoprofil og funn ved ikke-invasiv utredning. For pasienter med ST-elevasjonsinfarkt anbefales som tidligere umiddelbar koronar angiografi. Trombolytisk behandling anbefales som førstevalg ved sykehisto-

\section{Jarle Jortveit}

jarle.jortveit@sshf.no

Hjerteseksjonen

Medisinsk avdeling

Sørlandet sykehus Arendal

Bjørnar Grenne

Klinikk for hjertemedisin

St. Olavs hospital

Michael Uchto

Thomas Dahlslett

Liv Fosse

Pål Gunnes

Medisinsk avdeling

Sørlandet sykehus Arendal

Podkast på www.tidsskriftet.no

Engelsk oversettelse på www.tidsskriftet.no

> Se lederartikkel side 379

\section{HOVEDBUDSKAP}

De fleste pasienter med ST-elevasjonsinfarkt på Sørlandet og i Telemark ble i 2012 invasivt utredet og behandlet innen anbefalt tidsramme

Mange pasienter med hjerteinfarkt uten ST-elevasjon kom ikke til invasiv utredning innen tidsfristene som anbefales i nye retningslinjer

For å få tidligere invasiv utredning og behandling bør flere pasienter med hjerteinfarkt innlegges direkte på sykehus med PCl-beredskap 
rie $<2$ timer, tid til PCI-behandling $>90$ minutter og fravær av kontraindikasjoner (13).

Sørlandet sykehus Arendal har ansvar for invasiv behandling av koronarsykdom for pasienter bosatt i Vest-Agder, Aust-Agder og store deler av Telemark (totalt befolkningsgrunnlag ca. 450 000) og har døgnberedskap for behandling av akutt hjerteinfarkt.

Basert på data fra Norsk hjerteinfarktregister har vi undersøkt etterlevelse av retningslinjene for behandling av pasienter med hjerteinfarkt $(12,13)$ i vårt sykehusområde, og har spesielt lagt vekt på etterlevelsen av de nye retningslinjene for ikkeST-elevasjonsinfarkt (12). Vi har fokusert på tidsforsinkelsen fra første medisinske vurdering til invasiv utredning og behandling. Norsk hjerteinfarktregister ble fra 1.1. 2012 et nasjonalt kvalitetsregister med lovpålagt registrering av alle pasienter innlagt ved norske sykehus med hjerteinfarkt (jfr. hjerte- og karregisterforskriften $\S 2-1$ (16)). Infarktregisteret er en del av Hjerte- og karregisteret som er et landsdekkende personidentifiserbart register uten krav om samtykke fra den registrerte (jfr. helseregisterloven $\S 8$ (17)). Nasjonalt folkehelseinstitutt er databehandlingsansvarlig for registeret. Alle sykehus har tilgang til egne anonymiserte data til bruk i forskning og kvalitetssikring. Nasjonale data vil først foreligge i 2014 på grunn av forsinket oppstart ved mange sykehus.

\section{Materiale og metode}

Fra 1.1. 2012 ble alle pasienter innlagt ved Sørlandet sykehus Arendal med akutt hjerteinfarkt fortløpende registrert i Norsk hjerteinfarktregister. I denne studien har vi inkludert alle registrerte hjerteinfarkt i perioden 1.1. 2012-31.12. 2012. Antall hjerteinfarkt er kontrollert mot diagnosesøk i sykehusets pasientadministrative system. Opplysninger om tidligere sykdommer, risikofaktorer, symptomer, kliniske funn, utredning, behandling og forløp samt tidspunkter for symptomdebut, for innleggelse ved første sykehus og for behandling er registrert $i$ henhold til manual for Norsk hjerteinfarktregister (18). Alle registreringene er utført fortløpende av en spesialsykepleier ved utskrivning og er kvalitetssikret av en kardiolog før elektronisk innrapportering. Diagnosen akutt hjerteinfarkt ble satt på grunnlag av internasjonale anbefalinger og var basert på stigning og/eller fall i troponin og ett av følgende kriterier: iskemiske symptomer, ny ST-elevasjon/ST-depresjon/T-inversjon/venstre grenblokk, utvikling av patologisk Q-bølge, visuell fremstilling av ny myokardskade eller påvisning av intrakoronar trombe ved angiografi eller obduksjon (19). Sørlandet sykehus benytter troponin $\mathrm{T}$ som biokjemisk infarktmarkør og vi brukte i hen- hold til norsk praksis i 2012 troponin $\mathrm{T} \geq 30$ $\mathrm{ng} / \mathrm{l}$ som grense ved diagnosen akutt hjerteinfarkt.

Tidspunkt for eventuell første medisinske vurdering prehospitalt (legebesøk, ambulanse hos pasient, etc.) registreres ikke i Norsk hjerteinfarktregister. Vi har derfor valgt å bruke innleggelsestidspunkt ved første sykehus for registrering av tidsforløpet ved diagnostikk og behandling. I henhold til manual fra Norsk hjerteinfarktregister er tidspunkt for oppblåsing av første ballong i koronararterie benyttet som starttidspunkt for PCI hos pasienter der dette er utført. For pasienter der det ikke er utført PCI er tidspunkt for innleggelse av innføringshylse i arterien brukt som tidspunkt for prosedyrestart.

Data er analysert i statistikkprogrammet SPSS (versjon 18.0). Kontinuerlige variabler presenteres som gjennomsnitt \pm SD eller median (nedre, øvre kvartil), og forskjeller mellom grupper er analysert med T-test eller Mann-Whitneys U-test. Tiden fra symptomdebut til innleggelse og fra innleggelse til koronar angiografi/PCI er ikke normalfordelt, og presenteres derfor som median med interkvartilbredde. Kategoriske data presenteres som antall (\%), og forskjeller mellom grupper er analysert med khikvadrattest. Ved alle analyser er p-verdi $<0,05$ vurdert som statistisk signifikant.

\section{Resultater}

I 2012 behandlet Sørlandet sykehus Arendal 788 pasienter med akutt hjerteinfarkt. Av disse ble 269 (34,1\%) klassifisert som STelevasjonsinfarkt og $519(65,9 \%)$ klassifisert som ikke-ST-elevasjonsinfarkt. $220(81,8 \%)$ av pasientene med ST-elevasjonsinfarkt ble direkte innlagt ved Sørlandet sykehus Arendal. Blant pasientene med ikke-ST-elevasjonsinfarkt ble $172(33,1 \%)$ direkte innlagt. I denne pasientgruppen ble koronar angiografi utført hos $144(83,7 \%)$. De øvrige 347 (66,9\%) pasientene i denne gruppen - som alle fikk utført koronar angiografi ved Sørlandet sykehus Arendal - ble først innlagt ved et av de andre sykehusene i landsdelen, hovedsakelig Sørlandet sykehus Flekkefjord $(\mathrm{n}=33)$, Sørlandet sykehus Kristiansand $(n=102)$ og Sykehuset i Telemark $(n=202)$, mens ti kom fra andre sykehus. Vi mangler opplysninger om pasienter med hjerteinfarkt som ikke ble sendt videre til koronar utredning fra disse sykehusene, og om pasienter som eventuelt ble sendt til andre sykehus med PCI-tilbud. Kun 8 (1,5\%) av pasientene med ikke-ST-elevasjonsinfarkt som tilhørte annet lokalsykehus ble på grunn av kliniske funn prehospitalt og kort transportvei omdirigert direkte til Sørlandet sykehus Arendal.

Kliniske karakteristika ved pasientene fremgår av tabell 1. Det var ingen signifikante forskjeller mellom pasientgruppen

\section{RAMME 1}

European Society of Cardiologys nye anbefalinger for koronar angiografi hos pasienter med hjerteinfarkt uten ST-elevasjon (12)

- Umiddelbar angiografi < 2 timer

Pasienter med veldig høy risiko

- Refraktær angina

- Residiverende angina med ST-depresjon eller dype negative T-bølger i EKG til tross for antianginøs behandling

- Hjertesvikt eller hemodynamisk instabilitet

- Livstruende arytmier

- Tidlig angiografi < 24 timer

Pasienter med høy risiko

- Signifikant stigning eller fall i troponin

- Dynamiske ST- eller T-bølgeforandringer

som ble innlagt direkte ved invasivt senter og gruppen som ble overført fra annet sykehus med tanke på alder, kjønn, EKG-forandringer eller registrerte risikofaktorer. Dette gjaldt både ved ST-elevasjonsinfarkt og ikke-ST-elevasjonsinfarkt. Vi fant heller ingen signifikante forskjeller vedrørende angiografiresultat (data ikke vist), andel som fikk utført perkutan koronar intervensjon og sykehusmortalitet (tab 1).

Tidsforløpet fra symptomdebut til revaskularisering er vist $i$ tabell 2. Tiden fra symptomdebut til ankomst første sykehus var signifikant lavere hos pasienter innlagt direkte ved Sørlandet sykehus Arendal enn hos pasienter overflyttet fra andre sykehus. Ved ST-elevasjonsinfarkt var median tid fra innleggelse til koronar angiografi/PCI (dørtil-nål/ballong) signifikant kortere for pasienter direkte innlagt ved Sørlandet sykehus Arendal $(n=220)$ enn for pasienter som ble innlagt ved annet sykehus først og deretter overflyttet $(n=49)$. Kun tre $(6,1 \%)$ av pasientene med ST-elevasjonsinfarkt som ble overflyttet fikk trombolytisk behandling prehospitalt eller ved første sykehus.

Median tid fra innleggelse til koronar angiografi/PCI ved ikke-ST-elevasjonsinfarkt var også signifikant kortere for pasienter som ble innlagt direkte ved Sørlandet sykehus Arendal enn for pasienter som ble innlagt ved annet sykehus først (tab 2). Hos de direkte innlagte med ikke-ST-elevasjonsinfarkt ble det utført koronar angiografi/PCI innen to timer etter innleggelse hos $13(9,0 \%)$. Til sammenlikning ble fire $(1,2 \%)$ av pasientene med ikke-ST-elevasjonsinfarkt som ble innlagt ved annet sykehus først, angiografert 
Tabell 1 Kliniske karakteristika, andel som fikk utført perkutan koronar intervensjon (PCI) og sykehusdødelighet for pasienter med akutt hjerteinfarkt med ST-elevasjon (STEMI) og uten ST-elevasjon (nSTEMI) som fikk utført angiografi ved Sørlandet sykehus Arendal. Både pasienter som ble innlagt direkte ved Sørlandet sykehus Arendal og pasienter med hjerteinfarkt som ble overflyttet fra andre sykehus for koronar angiografi/PCl er inkludert. Der ikke annet er oppgitt, angis antall pasienter med prosentandel i parentes. Det forelå ingen signifikante forskjeller mellom pasientgruppene som ble innlagt direkte ved invasivt senter og gruppene som ble overflyttet fra annet sykehus

\begin{tabular}{|c|c|c|c|c|c|c|c|c|}
\hline \multirow[b]{3}{*}{ Menn } & \multicolumn{4}{|c|}{ ST-elevasjonsinfarkt } & \multicolumn{4}{|c|}{ Ikke-ST-elevasjonsinfarkt } \\
\hline & \multicolumn{2}{|c|}{$\begin{array}{l}\text { Direkte innlagt, } \\
\qquad N=220\end{array}$} & \multicolumn{2}{|c|}{$\begin{array}{c}\text { Overflyttet } \\
\text { fra annet sykehus, } \\
N=49\end{array}$} & \multicolumn{2}{|c|}{$\begin{array}{l}\text { Direkte innlagt, } \\
\qquad N=144^{1}\end{array}$} & \multicolumn{2}{|c|}{$\begin{array}{l}\text { Overflyttet fra } \\
\text { annet sykehus, } \\
N=347\end{array}$} \\
\hline & 171 & $(77,7)$ & 37 & $(75,5)$ & 97 & $(67,4)$ & 247 & $(71,2)$ \\
\hline Alder, gjennomsnittlig antall år \pm SD & 64,4 & $\pm 13,1$ & 63 & $\pm 13,7$ & 68, & $\pm 11,8$ & 67,2 & $\pm 12,4$ \\
\hline Alder $\geq 75$ år & 52 & $(23,6)$ & 7 & $(16,7)$ & 54 & $(37,5)$ & 112 & $(32,3)$ \\
\hline Tidligere hjerteinfarkt & 25 & $(11,4)$ & 10 & $(20,4)$ & 41 & $(28,5)$ & 111 & $(32,0)$ \\
\hline Røyking ${ }^{2}$ & 99 & $(45,0)$ & 21 & $(42,9)$ & 44 & $(30,6)$ & 103 & $(29,7)$ \\
\hline Hypertensjon & 74 & $(33,6)$ & 17 & $(34,7)$ & 60 & $(41,7)$ & 140 & $(40,3)$ \\
\hline Diabetes mellitus & 20 & $(9,1)$ & 5 & $(10,2)$ & 24 & $(16,7)$ & 74 & $(21,3)$ \\
\hline Ny eller ikke tidligere kjent EKG-forandring ${ }^{3}$ & 220 & $(100)$ & 49 & $(100)$ & 80 & $(55,6)$ & 203 & $(58,5)$ \\
\hline Utført PCl & 197 & $(89,5)$ & 44 & $(89,8)$ & 113 & $(78,5)$ & 260 & $(74,9)$ \\
\hline Sykehusmortalitet & 9 & $(4,1)$ & 0 & $(0,0)$ & 3 & $(2,1)$ & 2 & $(0,6)$ \\
\hline
\end{tabular}

1172 pasienter med ikke-ST-elevasjonsinfarkt ble direkteinnlagt ved Sørlandet sykehus Arendal. 144 av disse fikk utført koronar angiografi, mens de resterende 28 ikke ble angiografert. Kun pasienter som gjennomgikk angiografi er inkludert her

2 Nåværende eller tidligere røykere

${ }_{3}^{3} \mathrm{ST}$-elevasjon, ST-depresjon, venstre grenblokk eller T-bølgeforandringer

innen to timer. Koronar angiografi/PCI ved ikke-ST-elevasjonsinfarkt ble utført innen 24 timer hos $82(56,9 \%)$ av pasientene som ble direkte innlagt ved Sørlandet sykehus Arendal, og hos 119 (34,3\%) av pasientene med ikke-ST-elevasjonsinfarkt som ble overført fra annet sykehus ( $\mathrm{p} \leq 0,001)$.

$\mathrm{Vi}$ fant ingen statistisk signifikant forskjell i tid fra innleggelse til koronar angiografi/PCI hos pasienter som ble innlagt på en ukedag sammenliknet med pasienter som ble innlagt lørdag og søndag (data ikke vist).

\section{Diskusjon}

Denne studien har vist at de fleste pasienter med ST-elevasjonsinfarkt bosatt på Sørlandet og i Telemark kommer til invasiv utredning og behandling, innenfor anbefalte tidsfrister. For mange pasienter med hjerteinfarkt uten ST-elevasjon var det derimot lang forsinkelse til revaskulariserende behandling, og de fikk dermed ikke behandling innen tidsfristene som er anbefalt i europeiske retningslinjer.

Hos pasienter med ST-elevasjonsinfarkt var tiden fra symptomdebut til sykehusinnleggelse relativt kort. Dette kan antakelig tilskrives god prehospital diagnostikk med direkte overføring av EKG til sykehus, en effektiv ambulansetjeneste og få forsinkende mellomledd. Tiden fra ankomst sykehuset til revaskularisering (dør-til-nål/ballong) er også kort. Denne undersøkelsen bekrefter en godt fungerende behandlingskjede og høy grad av etterlevelse av behandlingsretningslinjene for de aller fleste pasienter med ST-elevasjonsinfarkt. Våre funn samsvarer også godt med tidligere studier av tidsforløpet til revaskularisering ved ST-elevasjonsinfarkt (20-22).

Noen pasienter med ST-elevasjonsinfarkt ble først innlagt ved sykehus uten mulighet for perkutan koronar intervensjon. Dette kan skyldes uklare symptomer, vanskelig tolkbart eller feiltolket EKG eller betydelig komorbiditet med behov for avklaring først. Hos kun tre av pasientene som ble innlagt med ST-elevasjonsinfarkt ved Sørlandet sykehus Arendal i 2012, var det gitt trombolytisk behandling prehospitalt. Hovedårsaken til at denne behandlingen er lite brukt i vårt sykehusområde, er sannsynligvis kort transporttid til invasivt senter. Etter vår mening bør likevel trombolytisk behandling prehospitalt eller på lokalsykehus vurderes hos flere pasienter med kort symptomtid og lang/forsinket transport også i vår region.

Tidlig revaskularisering også ved hjerteinfarkt uten ST-elevasjon i EKG er en av de største endringene i de nye retningslinjene for behandling av pasienter med akutt hjerteinfarkt (ramme 1) (12). Pasienter med ikke-ST-elevasjonsinfarkt anbefales nå koronar angiografi innen henholdsvis to eller 24 timer avhengig av risiko. European
Society of Cardiologys retningslinjer omhandler også pasienter med akutt koronarsyndrom uten hjerteinfarkt (12). Denne gruppen har lavere risiko og anbefales henholdsvis koronar angiografi innen 72 timer, koronar angiografi elektivt eller ingen invasiv utredning avhengig av risikoprofil og funn ved ikke-invasiv utredning. Pasienter med akutt koronarsyndrom uten hjerteinfarkt er ikke inkludert i denne studien.

Vi har ikke identifisert andre studier der man har undersøkt forsinkelse til revaskularisering ved ikke-ST-elevasjonsinfarkt med utgangspunkt $i$ de nye europeiske retningslinjene. Tidlig diagnose - både prehospitalt og ved ankomst sykehus - er vanskeligere ved ikke-ST-elevasjonsinfarkt enn ved STelevasjonsinfarkt fordi klare EKG-kriterier mangler. Norsk hjerteinfarktregister mangler detaljerte opplysninger om angiografiske funn, men fra andre studier estimeres at minst $30 \%$ av pasientene med ikke-STelevasjonsinfarkt har okklusjon av koronarkar og dermed burde vært invasivt utredet og behandlet umiddelbart (5). Vi mener at for få av pasientene med ikke-ST-elevasjonsinfarkt som innlegges direkte på Sørlandet sykehus Arendal, blir revaskularisert innen to timer. Påvisning av nye regionale forskjeller i myokardbevegelse ved ekkokardiografi kan bidra til å skille bedre mellom hjerteinfarkt med og uten koronar okklusjon (5). Ekkokar- 
Tabell 2 Tidsforløp fra symptomdebut til koronar angiografi/PCI hos pasienter med hjerteinfarkt med ST-elevasjon og uten ST-elevasjon, innlagt direkte ved Sørlandet sykehus Arendal og pasienter med hjerteinfarkt overflyttet fra andre sykehus

\begin{tabular}{|c|c|c|c|c|c|c|c|}
\hline & \multicolumn{3}{|c|}{ ST-elevasjonsinfarkt } & \multicolumn{4}{|c|}{ Ikke-ST-elevasjonsinfarkt } \\
\hline & $\begin{array}{l}\text { Direkte innlagt } \\
\quad \mathrm{n}=220\end{array}$ & $\begin{array}{c}\text { Overflyttet fra } \\
\text { annet sykehus } \\
n=49\end{array}$ & P-verdi & $\begin{array}{l}\text { Direkte innlagt } \\
\quad \mathrm{n}=144\end{array}$ & $\begin{array}{r}\text { Over } \\
\text { anne } \\
n\end{array}$ & $\begin{array}{l}\text { flyttet fra } \\
\text { t sykehus } \\
=347\end{array}$ & P-verdi \\
\hline $\begin{array}{l}\text { Median symptomtid' } \\
\text { (timer (nedre, øvre kvartil)) }\end{array}$ & $2,4 \quad(1,7,4,4)$ & $5,1 \quad(2,2,16,2)$ & 0,016 & $(1,7,17,2)$ & 11,5 & $(3,0,20,9)$ & 0,001 \\
\hline $\begin{array}{l}\text { Median dør til nål/ballong tid² } \\
\text { (timer (nedre, øvre kvartill)) }\end{array}$ & $0,5 \quad(0,3,1,1)$ & $3,3 \quad(2,1,15,6)$ & $<0,001$ & $19,2 \quad(4,1,29,7)$ & 27,7 & $(18,5,52,9)$ & $<0,001$ \\
\hline
\end{tabular}

1 Tid fra symptomdebut til ankomst første sykehus

2 Innleggelse første sykehus

diografi i akuttmottak er anbefalt som fast rutine i de nye retningslinjene for akutt koronarsyndrom uten ST-elevasjon (12). Nye ekkokardiografimodaliteter som måling av hjertemuskelens evne til deformasjon i rom (strain) kan bedre den diagnostiske presisjonen ytterligere (5). Ved Sørlandet sykehus Arendal gjennomføres tidlig ekkokardiografi i stadig større utstrekning hos pasienter med mistenkt ikke-ST-elevasjonsinfarkt for bedre å selektere pasienter til tidlig koronar angiografi/PCI. Likevel tror vi at ytterligere opplæring av leger i tilstedevakt og sterkere fokus på denne pasientgruppen $\mathrm{i}$ hele behandlingskjeden er nødvendig.

Svært få pasienter innlagt ved andre sykehus først har hatt mulighet til invasiv utredning og behandling innen to timer. For å behandle pasienter med ikke-ST-elevasjonsinfarkt og svært høy risiko etter gjeldende retningslinjer, kreves bedre prehospital diagnostikk og risikostratifisering, slik at disse kan håndteres på tilnærmet samme måte som pasienter med ST-elevasjonsinfarkt. Pasientene som etter nye retningslinjer bør ha umiddelbar koronar angiografi, må derfor transporteres direkte til invasivt senter. Flertallet av pasientene med ikke-ST-elevasjonsinfarkt $i$ vårt materiale hadde forandringer i EKG. Bedre telemedisinsk vurdering av prehospitalt EKG og overføring av kliniske opplysninger fra ambulanse til sykehuslege vil kunne forbedre seleksjonen av pasienter til umiddelbar koronar angiografi. Dette vil medføre noen endringer i dagens pasientflyt mellom sykehusene, men totalt sett mener vi det kan føre til redusert belastning på sykehusene i regionen, da de fleste av disse pasientene uansett angiograferes $i$ løpet av oppholdet.

Pasienter med hjerteinfarkt som ikke revaskulariseres akutt, anbefales i nye retningslinjer koronar angiografi innen 24 timer (såfremt det ikke foreligger kontraindikasjoner som f.eks. stor komorbiditet eller høy risiko for komplikasjoner). I vårt sykehusområde har vi bare delvis klart å implementere denne endringen. Andelen pasienter undersøkt med angiografi innen 24 timer er signifikant lavere i pasientgruppen som først innlegges ved et annet sykehus før de overflyttes til Sørlandet sykehus Arendal, enn for dem som legges inn direkte. For å kunne tilby tidligere invasiv utredning og behandling av ikke-ST-elevasjonsinfarkt må, etter vår oppfatning, pasienter med mistanke om akutt hjerteinfarkt og høy risiko også vurderes for innleggelse direkte ved sykehus med PCI-beredskap. Pasienter med brystsmerter som vurderes å ha lav risiko for hjerteinfarkt bør, som tidligere, innlegges lokalsykehus først for utredning.

Studien er basert på relativt få pasienter, kun ett invasivt senter og omfatter et begrenset geografisk område. Befolkningssammensetning og befolkningsmønster har derfor betydning for resultatene. Enkelte anamnestiske pasientopplysninger har manglet i registeret, og vi har ikke hatt mulighet til å komplettere disse senere. Tidspunkt for symptomdebut er basert på anamnese og er derfor forbundet med noe usikkerhet. Enkelte registerparametere er avhengig av en viss grad av individuell vurdering. Vi har forsøkt å unngå systematiske feil gjennom uavhengig lokal kvalitetssikring, men feilregistreringer kan likevel forekomme. Diagnosesøk i sykehusets pasientadministrative system er benyttet for å sikre komplett registrering av alle hjerteinfarkt. Pasienter som feilaktig ikke har fått diagnosen hjerteinfarkt ved utskrivning, er derfor ikke registrert i Norsk hjerteinfarktregister. Vi har ikke kunnet skille mellom pasienter med ikke-STelevasjonsinfarkt med svært høy og høy risiko, siden denne variabelen mangler i det nasjonale hjerteinfarktregisteret, og kan derfor ikke si hvor stor andel av pasientene som burde ha vært til angiografi innen to timer. Andelen pasienter med hjerteinfarkt som ikke ble utredet med koronar angiografi i vår region er heller ikke kjent, siden vi ikke har hatt tilgang til hjerteinfarktregistrene ved de øvrige sykehusene. En tilsvarende undersø- kelse av etterlevelse av behandlingsretningslinjer bør gjennomføres på nasjonalt nivå når nasjonale data fra Norsk hjerteinfarktregister foreligger

Tross nevnte begrensninger identifiserer denne studien et forbedringspotensial i behandlingen av pasienter med hjerteinfarkt uten ST-elevasjon. Etter vår oppfatning kan dette best løses ved at pasienter med sterk klinisk mistanke om akutt hjerteinfarkt innlegges direkte ved sykehus med PCI-beredskap.

\section{Jarle Jortveit (f. 1974)}

er spesialist i indremedisin og i hjertesykdommer, seksjonsoverlege og medlem av nasjonal rådgivningsgruppe i Norsk hjerteinfarktregister. Han har bidratt til idé, utforming, tolking av data, utarbeiding/revisjon av manus samt analysert data og utført litteraturs $\varnothing$.

Forfatter har fylt ut ICMJE-skjemaet og oppgir ingen interessekonflikter.

\section{Bjørnar Grenne (f. 1978)}

er ph.d. og tidligere lege i spesialisering ved Sørlandet sykehus Arendal, nå konstituert overlege ved St. Olavs hospital. Han har bidratt til idé, utforming, tolking av data og utarbeiding/revisjon av manus.

Forfatter har fylt ut ICMJE-skjemaet og oppgir ingen interessekonflikter.

\section{Michael Uchto (f. 1954)}

er spesialist i indremedisin og i hjertesykdommer og seksjonsoverlege ved $\mathrm{PCl}$-senteret Han har bidratt til idé, utforming, tolking av data og utarbeiding/revisjon av manus.

Forfatter har fylt ut ICMJE-skjemaet og oppgir ingen interessekonflikter.

\section{Thomas Dahlslett (f. 1981)}

er lege i spesialisering og stipendiat ved Hjerteseksjonen. Han har bidratt til idé, utforming, tolking av data og utarbeiding/revisjon av manus. Forfatter har fylt ut ICMJE-skjemaet og oppgir ingen interessekonflikter. 


\section{Liv Fosse (f. 1950)}

er spesialsykepleier og er ansvarlig for hjerteinfarktregisteret ved Sørlandet sykehus Arendal. Hun har bidratt til idé, utforming, tolking av data, utarbeiding/revisjon av manus samt utført datainnsamling.

Forfatter har fylt ut ICMJE-skjemaet og oppgir ingen interessekonflikter.

\section{Pål Gunnes (f. 1946)}

er spesialist i indremedisin og i hjertesykdommer, dr. med. og overlege ved $\mathrm{PCl}$-senteret. Han har bidratt til idé, utforming, tolking av data og utarbeiding/revisjon av manus. Forfatter har fylt ut ICMJE-skjemaet og oppgir ingen interessekonflikter.

Litteratur
1. Nasjonalt folkehelseinstitutt. Hjerte- og karsykdommer - faktaark med helsestatistikk www. fhi.no/eway/default.aspx?pid=239\&trg= List_6212\&Main_6157=6263:0:25,6067\& MainContent $6263=6464: 0: 25,6068 \&$ List $6212=62$ 18:0:25,8089:1:0:0:0:0 (31.5.2013)

2. Boersma E. Does time matter? A pooled analysis of randomized clinical trials comparing primary percutaneous coronary intervention and in-hospital fibrinolysis in acute myocardial infarction patients. Eur Heart J 2006; 27: 779-88.

3. Boersma E, Maas AC, Deckers JW et al. Early thrombolytic treatment in acute myocardial infarction: reappraisal of the golden hour. Lancet 1996 . 348: $771-5$

4. Perron A, Lim T, Pahlm-Webb U et al. Maximal increase in sensitivity with minimal loss of specificity for diagnosis of acute coronary occlusion achieved by sequentially adding leads from the 24-lead electrocardiogram to the orderly sequen- ced 12-lead electrocardiogram. J Electrocardiol 2007: 40: 463-9.

5. Grenne B, Eek C, Sjøli B et al. Acute coronary occlusion in non-ST-elevation acute coronary syndrome: outcome and early identification by strain echocardiography. Heart 2010; 96: 1550-6.

6. Koyama Y, Hansen PS, Hanratty CG et al. Prevalence of coronary occlusion and outcome of an immediate invasive strategy in suspected acute myocardial infarction with and without ST-segment elevation. Am J Cardiol 2002; 90: 579-84.

7. Wang TY, Zhang M, Fu Y et al. Incidence, distribution, and prognostic impact of occluded culprit arteries among patients with non-ST-elevation acute coronary syndromes undergoing diagnostic angiography. Am Heart J 2009; 157: 716-23.

8. Yeh RW, Sidney S, Chandra M et al. Population trends in the incidence and outcomes of acute myocardial infarction. N Engl J Med 2010; 362: 2155-65.

9. Terkelsen CJ, Lassen JF, Nørgaard BL et al. Mortality rates in patients with ST-elevation vs. nonST-elevation acute myocardial infarction: observations from an unselected cohort. Eur Heart J 2005; 26: $18-26$.

10. O'Donoghue M, Boden WE, Braunwald E et al. Early invasive vs conservative treatment strategies in women and men with unstable angina and nonST-segment elevation myocardial infarction: a meta-analysis. JAMA 2008; 300: 71-80.

11. Katritsis DG, Siontis GCM, Kastrati A et al. Optimal timing of coronary angiography and potential intervention in non-ST-elevation acute coronary syndromes. Eur Heart J 2011; 32: 32-40.

12. Hamm CW, Bassand JP, Agewall S et al. ESC Guidelines for the management of acute coronary syndromes in patients presenting without persistent ST-segment elevation: The Task Force for the management of acute coronary syndromes (ACS) in patients presenting without persistent ST-segment elevation of the European Society of Cardiology (ESC). Eur Heart J 2011; 32: 2999-3054.

13. Steg PG, James SK, Atar D et al. ESC Guidelines for the management of acute myocardial infarction in patients presenting with ST-segment elevation. Eur Heart J 2012; 33: 2569-619.
14. Kvalitetsutvalget NCS. ESC Guidelines for the management of acute coronary syndromes in patients presenting without persistent ST-segment elevation. Hjerteforum nr. 2/2012. https://legeforeningen.no/Fagmed/ Norsk-cardiologisk-selskap/Hjerteforum1/2012/ Hjerteforum-nr-2---2012/ (17.12.2013).

15. Benz B, Endresen K, Eritsland J. Revidert veileder for behandling av UAP/NSTEMI i Helse Sør- Øst. Oslo: Helse Sør-Øst, 2012

16. FOR 2011-12-16 nr. 1250: Forskrift om innsamling og behandling av helseopplysninger i Nasjonalt register over hjerte- og karlidelser (Hjerte- og karregisterforskriften). www.lovdata.no/cgi-wift/ Idles?doc=/sf/sf/sf-20111216-1250.html\#3-3 (17.12.2013).

17. LOV 2001-05-18 nr. 24: Lov om helseregistre og behandling av helseopplysninger (helseregisterloven). www.lovdata.no/all/ tl-20010518-024-002.html\#8 (17.12.2013)

18. Norsk hjerteinfarktregister. Brukermanual. www.helse-midt.no/no/HF/HEMIT/MRS/ Hjerteinfarktregister/Horisontal-meny-1/ Manualer/67571/ (17.12.2013).

19. Thygesen K, Alpert JS, Jaffe AS et al. Third universal definition of myocardial infarction. Eur Heart J 2012; 33: 2551-67.

20. Lambert L, Brown K, Segal E et al. Association between timeliness of reperfusion therapy and clinical outcomes in ST-elevation myocardial infarction. JAMA 2010; 303: 2148-55.

21. Cannon CP, Gibson CM, Lambrew CT et al. Relationship of symptom-onset-to-balloon time and door-to-balloon time with mortality in patients undergoing angioplasty for acute myocardial infarction. JAMA 2000; 283: 2941-7.

22. Post F, Giannitsis E, Riemer T et al. Pre- and early in-hospital procedures in patients with acute coronary syndromes: first results of the «German chest pain unit registry». Clin Res Cardiol 2012; 101: 983-91.

Mottatt 8.3. 2013, første revisjon innsendt 7.6. 2013, godkjent 17.12. 2013. Redaktør: Merete Kile Holtermann. 